\title{
Serine/threonine protein phosphatase 5 regulates glucose homeostasis in vivo and apoptosis signalling in mouse pancreatic islets and clonal MIN6 cells
}

\author{
N. Grankvist • L. Amable • R. E. Honkanen • \\ Å. Sjöholm $\cdot$ H. Ortsäter
}

Received: 9 December 2011 / Accepted: 2 March 2012 / Published online: 12 April 2012

(C) Springer-Verlag 2012

\begin{abstract}
Aims/hypothesis During the development of type 2 diabetes mellitus, beta cells are often exposed to a high glucose/ hyperlipidaemic environment, in which the levels of reactive oxygen species (ROS) are elevated. In turn, ROS can trigger an apoptotic response leading to beta cell death, by activating mitogen-activated protein kinase (MAPK) signalling cascades. Here we test the hypothesis that serine/threonine protein phosphatase 5 (PP5) acts to suppress proapoptotic c-Jun N-terminal kinase (JNK) signalling in beta cells. Methods Ppp5 $c^{-/-}$and Ppp5c $c^{+/+}$mice were subjected to intraperitoneal glucose (IPGTT) or insulin tolerance tests. Pancreatic islets from $P p p 5 c^{-/-}$and $P p p 5 c^{+/+}$mice or MIN6 cells treated with short-interfering RNA targeting PP5 were exposed to palmitate or $\mathrm{H}_{2} \mathrm{O}_{2}$ to activate MAPK signalling. Changes in protein phosphorylation, mRNA expression, apoptosis and insulin secretion were detected by western blot analysis, quantitative RT-PCR or ELISA.

Results Ppp5c $\mathrm{c}^{-/}$mice weighed less and exhibited reduced fasting glycaemia and improved glucose tolerance during
\end{abstract}

Electronic supplementary material The online version of this article (doi:10.1007/s00125-012-2541-1) contains peer-reviewed but unedited supplementary material, which is available to authorised users.

N. Grankvist • R. E. Honkanen · Å. Sjöholm · H. Ortsäter $(\square)$

Department of Clinical Science and Education,

Karolinska Institutet,

Södersjukhuset,

11883 Stockholm, Sweden

e-mail: henrik.ortsater@sodersjukhuset.se

L. Amable $\cdot$ R. E. Honkanen

Department of Biochemistry and Molecular Biology,

University of South Alabama, College of Medicine,

Mobile, AL, USA
IPGTT, but retained normal insulin sensitivity and islet volume. Comparison of MAPK signalling in islets from $P_{p p 5 c^{-/-}}$mice and MIN6 cells revealed that the lack of PP5 was associated with enhanced $\mathrm{H}_{2} \mathrm{O}_{2}$-induced phosphorylation of JNK and c-Jun. Cells with reduced PP5 also showed enhanced JNK phosphorylation and apoptosis after palmitate treatment. PP5 suppression in MIN6 cells correlated with hypersecretion of insulin in response to glucose.

Conclusions/interpretation PP5 deficiency in mice is associated with reduced weight gain, lower fasting glycaemia, and improved glucose tolerance during IPGTT. At a molecular level, PP5 helps suppress apoptosis in beta cells by a mechanism that involves regulation of JNK phosphorylation.

Keywords Apoptosis - Diabetes - Oxidative stress · Pancreatic islet $\cdot$ Protein phosphatase 5

\begin{tabular}{|c|c|}
\hline Abbreviations & \\
\hline ASK1 & Apoptosis signalling kinase 1 \\
\hline Carboxy-DCF & 5-(and-6)-Carboxy-2', $7^{\prime}$ \\
\hline & -dichlorodihydrofluorescein diacetate \\
\hline cDNA & Complementary DNA \\
\hline GR & Glucocorticoid receptor \\
\hline IPGTT & Intraperitoneal glucose tolerance test \\
\hline JNK & c-Jun N-terminal kinase \\
\hline MAPK & Mitogen-activated protein kinase \\
\hline MAPKK & Mitogen-activated protein kinase kinase \\
\hline MAPKKK & $\begin{array}{l}\text { Mitogen-activated protein kinase } \\
\text { kinase kinase }\end{array}$ \\
\hline PP5 & Protein phosphatase 5 \\
\hline PPAR & Peroxisome proliferator activated receptor \\
\hline PPP & Phosphoprotein phosphatase \\
\hline ROS & Reactive oxygen species \\
\hline siRNA & Short-interfering RNA \\
\hline TPR & Tetratricopeptide repeat \\
\hline
\end{tabular}




\section{Introduction}

In healthy individuals, fasting blood glucose concentrations increase from about $4-5 \mathrm{mmol} / \mathrm{l}$ to $7-8 \mathrm{mmol} / \mathrm{l}$ after a meal [1]. As insulin resistance develops, glucose uptake becomes impaired, and normoglycaemia is maintained by compensatory hypersecretion of insulin [2], mainly due to an increase in pancreatic beta cell mass [3-5]. After the development of type 2 diabetes, beta cells are exposed chronically to supraphysiological glucose concentrations, which can result in reduced beta cell mass [3,5]. Since type 2 diabetes is often linked to obesity, in conjunction with elevated glucose levels, beta cells in type 2 diabetes patients are also often exposed to a hyperlipidaemic environment, producing so-called glucolipotoxicity. Elevated levels of glucose and fatty acids are associated with increased production of reactive oxygen species (ROS) [6-8]. Mounting evidence suggests that ROS act as signalling intermediates and play important roles in a variety of cellular responses. Notably, when present at high levels, ROS cause oxidative stress and cellular damage, which can initiate apoptosis in isolated human pancreatic islets [9]. Because beta cells express low levels of ROS-scavenging enzymes $[10,11]$, they are highly susceptible to ROS.

To cope with oxidative stress, cells are equipped with various signal-transduction networks. The mitogenactivated protein kinase (MAPK) pathways are important for an optimal response to counter oxidative stress. MAPK cascades are generally three-tiered signalling modules, in which sequential phosphorylation propagates and amplifies the signal. In these cascades, the catalytic activity of the downstream MAPK is activated by a MAPK kinase (MAPKK)-mediated phosphorylation. MAPKKs are activated in a similar manner by MAPKK kinases (MAPKKKs). Apoptosis signalling kinase 1 (ASK1) is a MAPKKK that plays a key role in oxidative-stress-induced cell death. ASK1 activates two MAPKKs (MKK4 and MKK6). In turn, MKK4 and MKK6 phosphorylate c-Jun N-terminal kinases (e.g. JNK1, JNK2) and p38 MAPKs at sites that enhance their catalytic activity [12-14]. JNKs and p38 MAPKs induce a variety of cellular functions, notably gene expression and apoptosis, through the phosphorylation of specific serine and/or threonine residues of their substrate proteins. When altered, the dysregulation of MAPK signalling networks has been linked to the pathogenesis of several disease states, including cancer, ischaemic injury and diabetes [15].

The ability of ASK1 to respond to ROS is mediated in part by its interaction with an antioxidant protein, thioredoxin [16]. Thioredoxin binds ASK1, inhibiting ASK1 activity. When proper pro-oxidant/antioxidant balances are maintained, reduced thioredoxin binding to ASK1 helps to suppress apoptosis. Upon oxidation, thioredoxin dissociates from ASK1 inducing a JNK-mediated cascade leading to apoptosis. Hence, activation of ASK1 and the subsequent activation of JNK and p38 MAPK is responsive to changes in the level of ROS. To help protect cells from the accidental activation of ASK1 and apoptosis, the catalytic activity of ASK1 is further regulated by phosphorylation. Oxidative stress induces ASK1 phosphorylation on Thr845, which correlates with an increase in both ASK1 activity and ASK1-dependent apoptosis [17, 18]. ASK1 is further regulated by serine/threonine protein phosphatase 5 (PP5; encoded by PPP 5C), an okadaic acid/microcystin/calyculin A [19] sensitive serine/threonine protein phosphatase that belongs to the phosphoprotein phosphatase (PPP) family of enzymes [20]. The expression of PPP 5C is transcriptionally induced by hypoxia/ROS via the activation of hypoxia-inducible transcription factor $1 \alpha$ [21]. At high levels, ROS also induce the association of PP5 with ASK1, which is associated with dephosphorylation of Thr845 and the inactivation of ASK1 [22-24]. These observations suggest that PP5 can help suppress oxidative-stress-induced apoptosis, by preventing the sustained activation of ASK1 and the subsequent activation of JNK.

Like other PPPs (PP1, PP2A, PP2B/calcineurin, PP4, PP6 and PP7), PP5 is conserved among species. Although PPP5C is expressed in most, if not all, mammalian cells, the role(s) of PP5 in biology is only beginning to emerge [25-27]. The role of PP5 in beta cell function is entirely unknown. The associations mentioned above, however, suggest that it may play a role in the regulation of cellular responses to stress, acting as a negative regulator of the JNK- and/or p38-signalling cascades that facilitate apoptosis. The present study further investigates the role of PP5 in mice and explores the molecular mechanisms regulated by PP5 in isolated pancreatic islets and clonal beta cells exposed to $\mathrm{H}_{2} \mathrm{O}_{2}$ or palmitate.

\section{Methods}

Animals and isolation of islets of Langerhans We have generated PP5 knockout (Ppp5 $\mathrm{c}^{-/-}$) mice [27], and experiments were performed on 2-8-month-old male animals. Glucose handling was evaluated by an i.p. glucose tolerance test (IPGTT). The mice were fasted $(4 \mathrm{~h})$ before they received i.p. injections containing a $30 \%$ glucose solution ( $2 \mathrm{~g} / \mathrm{kg}$ body weight). Blood was drawn from the tail vein, and glycaemia was measured using a glucometer (OneTouch Ultra 2; LifeScan, Milpitas, CA, USA) immediately before (time 0) and 5, 15, 30, 60 and 120 min after the injection. Insulin sensitivity was determined by an i.p. insulin tolerance test. Random-fed mice were injected i.p. with human recombinant insulin (Humalog; Eli Lilly, Indianapolis, IN, USA) equivalent to 1 unit $/ \mathrm{kg}$ body weight. Blood glucose levels were measured as described above. 
Mice were killed by exposure to $\mathrm{CO}_{2}$ followed by decapitation. The pancreatic gland was excised, and islets were isolated by collagenase digestion. Islets were placed in RPMI-1640 culture medium (SVA, Uppsala, Sweden) containing $11 \mathrm{mmol} / \mathrm{l}$ glucose and supplemented with $10 \% \mathrm{FBS}$, $2 \mathrm{mmol} / 1$ L-glutamine (SVA), $6 \mathrm{mg} / \mathrm{ml}$ penicillin $\mathrm{G}$ and $5 \mathrm{mg} / \mathrm{ml}$ streptomycin sulphate (Invitrogen, Carlsbad, CA, USA) for an overnight recovery at $37^{\circ} \mathrm{C}$ in $5 \% \mathrm{CO}_{2}$. The next day, islets were transferred to medium (described above) without FBS and supplemented with palmitate $(0.5 \mathrm{mmol} / \mathrm{l})$ equilibrated with $0.5 \%$ BSA (fraction V fatty acid free; Roche Diagnostics, Mannheim, Germany). The study was performed according to the guidelines of Karolinska Institutet and approved by the local animal ethics committee.

MIN6 cell culture and in vitro treatment MIN6 cells [28], derived from mouse pancreatic beta cells, were maintained in DMEM containing sodium pyruvate and $25 \mathrm{mmol} / \mathrm{l}$ glucose, and supplemented with $15 \% \mathrm{FBS}, 6 \mathrm{mg} / \mathrm{ml}$ penicillin $\mathrm{G}$, $5 \mathrm{mg} / \mathrm{ml}$ streptomycin sulphate, $2 \mathrm{mmol} / \mathrm{l} \mathrm{L}$-glutamine and $50 \mu \mathrm{mol} / \mathrm{l} \beta$-mercaptoethanol at $37^{\circ} \mathrm{C}$ and $5 \% \mathrm{CO}_{2} . \mathrm{H}_{2} \mathrm{O}_{2}$ was diluted in the above medium to a final concentration of $0.5 \mathrm{mmol} / \mathrm{l}$. During palmitate exposure, $0.5 \mathrm{mmol} / \mathrm{l}$ palmitate equilibrated with $0.5 \% \mathrm{BSA}$ was added.

Suppression of PP5 in cultured cells using siRNA Short interfering RNAs (siRNAs) targeting three different regions of mouse PP5 (NM_011155), or the corresponding scrambled siRNA (negative control; Santa Cruz Biotechnology, Santa Cruz, CA, USA), were used to suppress PP5 expression in MIN6 cells. Cell transfection was aided by electroporation, using a Nucleofector (Lonza, Cologne, Germany) and $100 \mathrm{pmol} / \mathrm{l}$ of the indicated siRNA.

Analysis of ROS levels 5-(and-6)-Carboxy-2',7'-dichlorodihydrofluorescein diacetate (carboxy-DCF) was used as a fluorogenic indicator to detect ROS. Cellular levels of ROS were measured using the Image-iT LIVE Green Reactive Oxygen Species Detection Kit (Invitrogen) as described previously [29].

Assessment of cell viability and apoptosis Cell viability was assessed by a Cytotoxicity Detection Kit ${ }^{\text {Plus }}$ (Roche Diagnostics), which measures the amount of lactate dehydrogenase released after cell lysis, which correlates inversely with the amount of living cells. Apoptosis was detected by measuring cytoplasmic DNA-histone nucleosomes generated during apoptotic DNA fragmentation using the Cell Death Detection Kit ELISA $^{\text {PLUS }}$ (Roche Diagnostics), according to the manufacturer's instructions.

Western blot analyses Protein samples from islets or cells were prepared for western blot analysis as previously described [30]. Total protein concentrations were determined as described by Lowry et al [31]. Immunoblot analyses were performed using antibodies that recognise PP5 (Santa Cruz Biotechnology), phosphorylated p38 MAPK, total p38 MAPK, phosphorylated JNK, total JNK, phosphorylated c-Jun, total c-Jun and the cleaved form of caspase 3 (Cell Signaling Technology, Danvers, MA, USA). Immunoreactive bands were detected using ECL (GE Healthcare, Uppsala, Sweden), imaged with a GelDoc system and quantified with Quantity One software (Bio-Rad Laboratories, Hercules, CA, USA). To verify equal protein loading after imaging, the polyvinylidene difluoride membranes were stained with Coomassie Blue.

Quantitative PCR Total mRNA was isolated from cells and islets. Complementary DNA (cDNA) was produced using reverse transcriptase (iScript cDNA Synthesis Kit; Bio-Rad). The expression levels of mRNAs were measured by SYBR green-based quantitative RT-PCR (iQ SYBR Green Supermix). Actb was used as an internal standard (for primer details, see electronic supplementary material [ESM] Table 1).

Analysis of insulin, C-peptide and PP2A phosphatase activity Glucose-stimulated insulin release and insulin content were measured in MIN6 cells after transfection with siRNA targeting PP5 or a negative control siRNA, after treatment with or without $0.5 \mathrm{mmol} / \mathrm{l}$ palmitate, as previously described [30]. The amount of insulin was determined using an insulin ELISA (Mercodia, Uppsala, Sweden). Quantification of C-peptide in serum was determined by ELISA (ALPCO Diagnostics, Salem, NH, USA), as instructed by the manufacturer. PP2A activity was determined by using a PP2A-specific immunoprecipitation phosphatase assay kit (Millipore, Temecula, CA, USA), which measures free phosphate with malachite green dye. The assay was performed according to the manufacturer's instructions.

Immunohistochemistry Pancreatic glands were dissected and placed in $4 \%$ phosphate-buffered paraformaldehyde for $48 \mathrm{~h}$. The fixed pancreas was then embedded in paraffin and sectioned at $5 \mu \mathrm{m}$ longitudinally through the entire gland. Sections were stained for insulin (guinea pig antiinsulin polyclonal; Dako, Glostrup, Denmark) and counterstained with haematoxylin and eosin. For quantification of islet volume, we adopted the nucleofector method [32] using a computerised setup for stereology, driven by newCAST software (Visiopharm, Hoersholm, Denmark). For each animal, the volume was determined from all islets identified (ranging from 87 to 125 per animal) in three randomly chosen sections and presented as the mean islet volume.

Statistical analysis Data are presented as mean \pm SEM. Student's $t$ test was used to compare the difference between two 
groups. For multiple comparisons, differences were determined by one- or two-way ANOVA followed by the Bonferroni post hoc test (GraphPad Prism version 5 software). A value of $p<0.05$ was considered significant.

\section{Results}

Comparison of body weight, glucose tolerance and insulin sensitivity in Ppp5c $c^{+/+}$and $P p p 5 c^{-/}$mice To characterise the biological actions of PP5, we recently generated $P p p 5 c^{-/}$ mice [27]. As reported for other tissues [27], western blot analysis detected no PP5 protein in islets from Ppp5 $5 c^{-1-}$ animals, whereas PP5 was easily detected in islets from $P p p 5 c^{+/+}$animals (Fig. 1a). When compared over a time period of 2-8 months of age, the weight of male $P p p 5 c^{-1-}$ mice was significantly less than littermate $P p p 5 c^{+/+}$mice (Fig. 1b). Mice lacking PP5 also had lower fasting glycaemia than littermate controls (Fig. 1c), but unchanged fasting serum insulin levels (Fig. 1d). However, C-peptide levels were increased in $P p p 5 c^{-/}$mice (Fig. 1e), which led to an increase in the C-peptide to insulin ratio $\left(1.4 \pm 0.4 \mathrm{in} P p p 5 c^{+/+}\right.$mice vs $4.1 \pm 1.1$ in $P p p 5 c^{-/}$mice, $\left.p<0.05\right)$. We also counted the number of islets and quantified mean islet volume from histological sections obtained from $P p p 5 c^{-/-}$and $P p p 5 c^{+/+}$ mice, but no differences were found (Fig. $1 \mathrm{~h}$ and data not shown). Blood glucose levels during an IPGTT were reduced in Ppp5 $\mathrm{c}^{-/}$mice (Fig. 1f), while no difference in insulin sensitivity was observed between the two genotypes (Fig. 1g).

Expression of other protein phosphatases is not altered after PP5 silencing After either genetic disruption of PP5 in mice or siRNA suppression of PP5 in MIN6 cells, mRNA levels of related PPP-family phosphatases (Ppplca, Ppp2ca and $P p p 3 c a /$ calcineurin) were not upregulated to compensate for PP5 deficiency (ESM Fig. 1a, b). Commensurate with mRNA data, siRNA targeting PP5 did not have any effect on PP2A activity (ESM Fig. 1c).

Characterisation of Ppp5c expression levels in islets of Langerhans and MIN6 cells The expression of Ppp5c mRNA was readily detected in both pancreatic islets isolated from $P p p 5 c^{+/+}$(wild-type) mice and MIN6 cells. In both, the expression level of $P p p 5 c$ mRNA was similar to that of $S l c 2 a 2$ and $G c k$, but lower than Ins 2 mRNA expression and that of the housekeeping genes, Actb and Gapdh (ESM Fig. 2a, b). In MIN6 cells, neither glucose nor palmitate had an apparent effect on PP5 protein levels (ESM Fig. 2c).

Isolated islets from Ppp5c ${ }^{-/}$mice show increased sensitivity towards palmitate-induced activation of JNK signalling and apoptosis Under pre-diabetic and diabetic conditions, beta cells are under increased oxidative pressure due to both hyperlipidaemia and hyperglycaemia [6]. To examine the role of PP5 under such conditions, pancreatic islets isolated from $P p p 5 c^{+/+}$or $P p p 5 c^{-/}$mice were treated in vitro with $0.5 \mathrm{mmol} / \mathrm{l}$ palmitate in the presence of $11 \mathrm{mmol} / \mathrm{l}$ glucose for $24 \mathrm{~h}$. Enhanced formation of cleaved caspase 3 was observed after exposure, with the level of apoptosis further enhanced in the $P p p 5 c^{-/-}$islets compared with $P p p 5 c^{+/+}$ islets (Fig. 2a). The augmented apoptosis in $P p p 5 c^{-/}$islets correlated with enhanced phosphorylation of JNK1 (Fig. 2b) and was also associated with elevated levels of JNK2 protein (Fig. 2c).

siRNA-mediated suppression of PP5 augments $\mathrm{H}_{2} \mathrm{O}_{2}$-induced activation of JNK signalling in MIN6 cells MIN6 cells were used to further investigate the role of PP5 in beta cells. First, the effects of $\mathrm{H}_{2} \mathrm{O}_{2}$ on MAPK signalling were characterised. After a $30 \mathrm{~min}$ exposure to $0.5 \mathrm{mmol} / 1 \mathrm{H}_{2} \mathrm{O}_{2}$, cellular levels of ROS increased (Fig. 3a), which was associated with a marked increase in JNK phosphorylation. JNK1 phosphorylation increased by $690 \pm 9 \%$ and JNK 2 phosphorylation by $1,100 \pm 60 \%$ after a 15 min exposure (Fig. 3b). A similar increase in phosphorylation was seen for both c-Jun and p38 MAPK (Fig. 3c, d). When cell viability was measured $30 \mathrm{~min}$ after treatment, it was only reduced by $5 \%$ (Fig. 3e). However, the $30 \mathrm{~min}$ exposure to $0.5 \mathrm{mmol} /$ $1 \mathrm{H}_{2} \mathrm{O}_{2}$ was sufficient to inflict irreversible cell damage (i.e. when cells were treated for $30 \mathrm{~min}$ and then incubated in the absence of $\mathrm{H}_{2} \mathrm{O}_{2}, \sim 75 \%$ of the cells were dead after $8 \mathrm{~h}$ [Fig. 3e]). The effects of $\mathrm{H}_{2} \mathrm{O}_{2}$ could be reversed completely by supplementing the incubation medium with the ROSscavenging enzyme, catalase (Fig. $3 f$ and data not shown).

To determine if PP5 can suppress MAPK signalling, MIN6 cells were transfected with siRNA targeting PP5, which by $48 \mathrm{~h}$ after transfection reliably suppressed PP5 mRNA and protein levels by $75 \%$ and $85 \%$, respectively (Fig. 4a, b). The suppression of PP5 was associated with increased sensitivity towards $\mathrm{H}_{2} \mathrm{O}_{2}$-induced phosphorylation of JNK1 and JNK2 (Fig. 4c, d). c-Jun was also hyperphosphorylated in cells after siRNA-mediated suppression of PP5 (data not shown). However, $\mathrm{H}_{2} \mathrm{O}_{2}$-induced phosphorylation of p38 MAPK was not affected by the loss of PP5 (Fig. 6e). Neither cellular levels of ROS nor expression of scavenging enzymes was affected by siRNA targeting PP5 (Fig. 4f, g). These observations indicate that acute exposure of MIN6 cells to $\mathrm{H}_{2} \mathrm{O}_{2}$ promotes JNK signalling, with PP5 acting as a negative regulator of JNK phosphorylation.

Suppression of Ppp5c expression augments palmitateinduced phosphorylation of JNK, c-Jun and apoptosis in MIN6 cells MIN6 cells were exposed to palmitate 
Fig. 1 Comparison of body weight, glucose tolerance and insulin sensitivity in $\mathrm{Ppp} 5 \mathrm{c}^{+/+}$ (white circles and bars) and $P p p 5 c^{-/-}$(black circles and bars) mice. a PP5 protein production in different tissues (as indicated) from $P p p 5 c^{+/+}$ and $P p p 5 c^{--}$mice was detected by western blot analysis. b Body weights of $P p p 5 c^{+/+}$and $P p p 5 c^{-/-}$mice $(n=9-13)$ were measured over time. c Fasting blood glucose concentrations (2 months [ $n=11], 3$ months $[n=27]$, 4 months $[n=5-6]$ and 6 months $[n=21])$ were determined with a glucometer. d Fasting insulin levels in the serum were determined using an insulin ELISA (2 months $[n=16-23], 3$ and 4 months $[n=4-5])$. e C-peptide levels in the serum were determined by ELISA $(n=7)$. Mice from both strains were subjected to either an IPGTT $(n=4-5)(\mathbf{f})$ or an i.p. insulin tolerance test $(n=3)$ (g). h Islet volume was evaluated by stereology at $\times 10$ magnification $(n=3-4)$.

Data represent mean \pm SEM.

* denotes a significant difference $(p<0.05)$ between $P p p 5 c^{+/+}$and $P p p 5 c^{-/-}$mice a

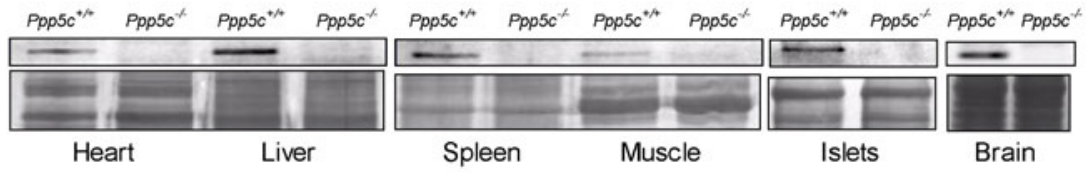

b

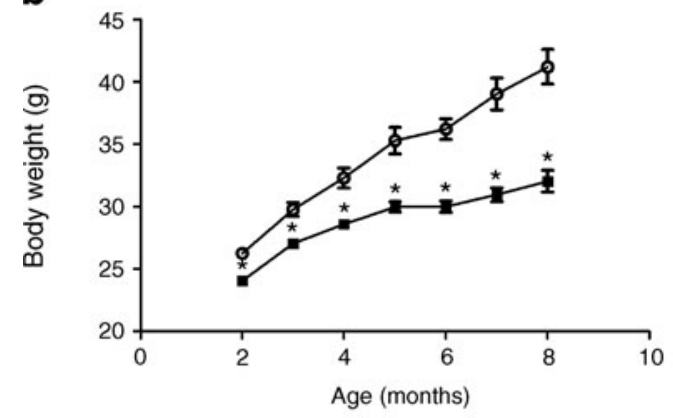

d

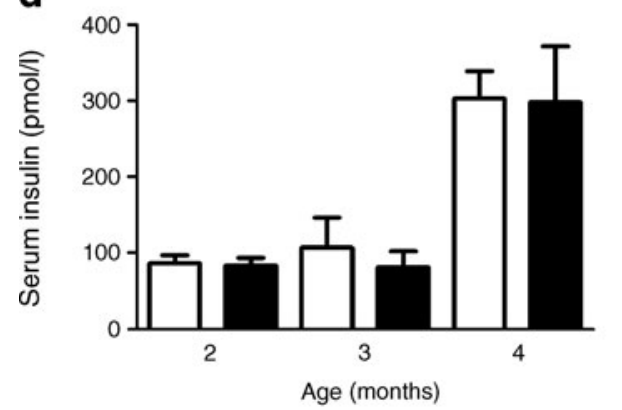

f
C

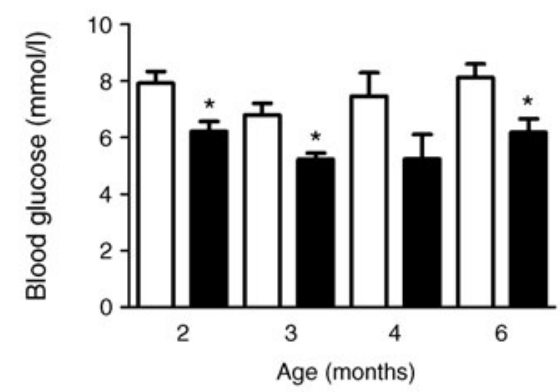

e

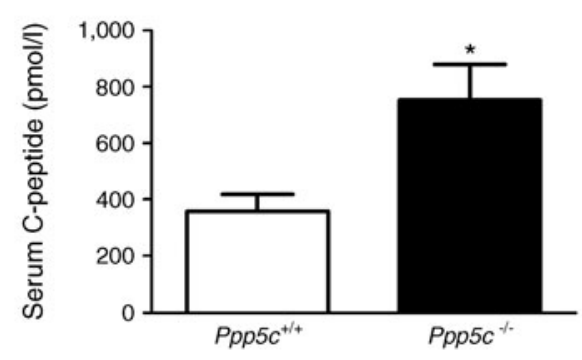

g

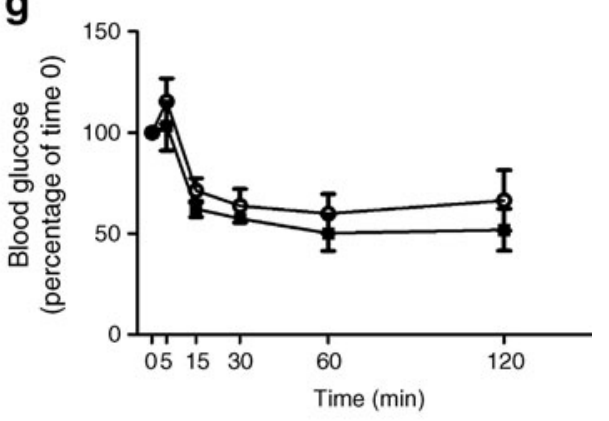

h

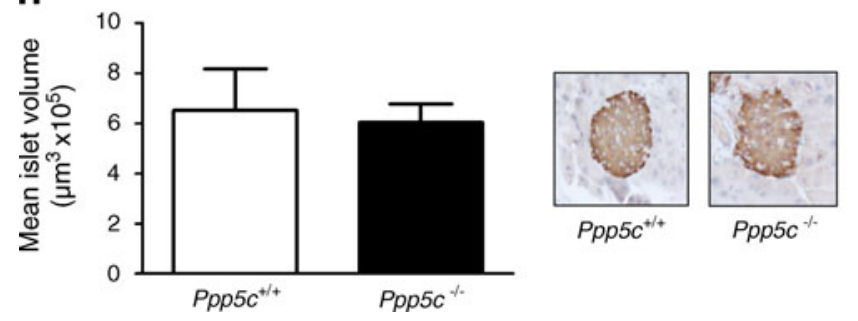

$(0.5 \mathrm{mmol} / \mathrm{l})$ in combination with either 5.5 or $25 \mathrm{mmol} / \mathrm{lglu}-$ cose for $24 \mathrm{~h}$. In the presence of $25 \mathrm{mmol} / \mathrm{l}$ glucose, palmitate treatment increased MAPK signalling, as evidenced by the increased phosphorylation levels of JNK1 and JNK2
(Fig. 5a) and their downstream target, c-Jun (Fig. 5b). These data suggest that palmitate, in the presence of high glucose (25 mmol/l), activates the JNK arm of the signalling network. However, it should be noted that, although the effect was not as 

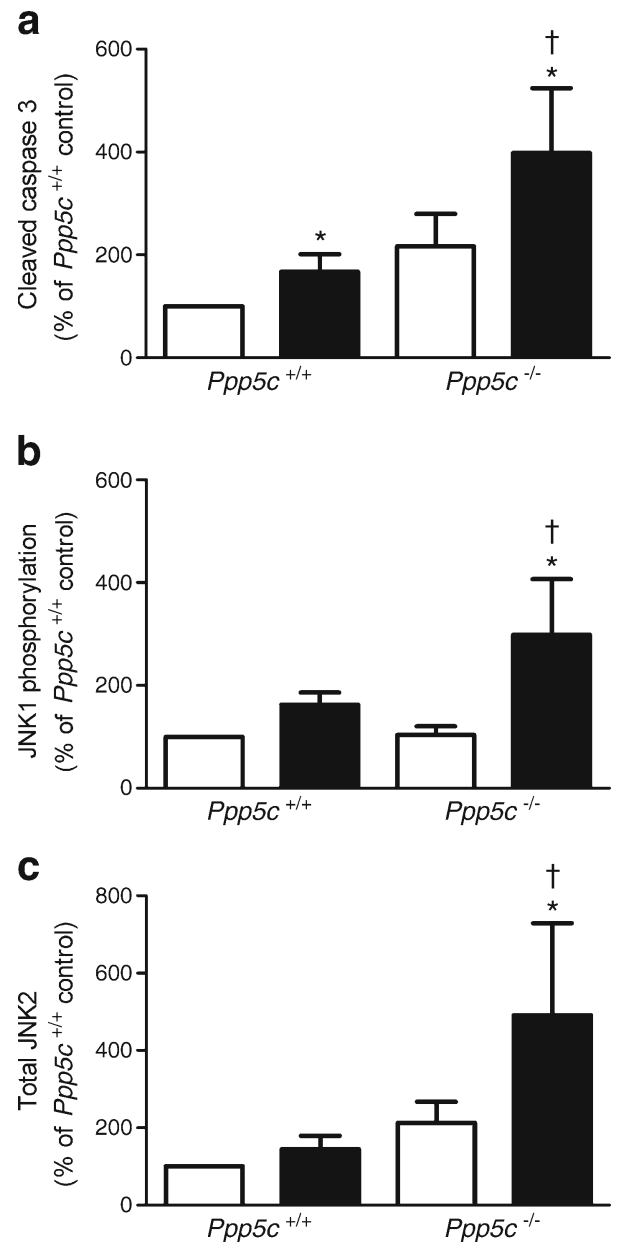

Fig. 2 PP5 disruption increases JNK activation and augments lipoapoptosis in mouse pancreatic islets. Islets were isolated from the indicated strains of mice and treated with (black bars) or without (white bars) $0.5 \mathrm{mmol} / 1$ palmitate equilibrated with $0.5 \%$ BSA for $24 \mathrm{~h}$. a Comparison of palmitate-induced apoptosis between $P p p 5 c^{+/+}$and Ppp5 $\mathrm{c}^{-/}$islets performed by measuring protein levels of cleaved caspase 3 by western blot analysis. Phosphorylation levels of JNK1 (b) together with the total JNK2 levels (c) were detected by western blot analysis. Bars represent mean \pm SEM, $n=7-8$. * denotes a significant difference $(p<0.05)$ between palmitate and controls; ${ }^{\dagger}$ denotes a significant difference $(p<0.05)$ between $P p p 5 c^{+/+}$and Ppp5 $c^{-/-}$mice

pronounced, palmitate-induced JNK1 and JNK2 phosphorylation was also observed in cells cultured in the presence of $5.5 \mathrm{mmol} / \mathrm{l}$ glucose (Fig. $5 \mathrm{c}$ ). As expected, palmitate treatment was associated with elevated levels of ROS (Fig. 5d). No activation of p38 MAPK was observed in MIN6 cells after palmitate exposure at either 5.5 or $25 \mathrm{mmol} / \mathrm{l}$ glucose (Fig. 5e). As previously reported $[9,30,33,34]$, palmitate treatment increased caspase 3 cleavage and enhanced DNA fragmentation, both hallmarks of apoptotic cell death (Fig. 5f, g).

Next, the effects of palmitate were evaluated in MIN6 cells with reduced levels of PP5. In concordance with the results obtained using $\mathrm{H}_{2} \mathrm{O}_{2}$, susceptibility to palmitate was a

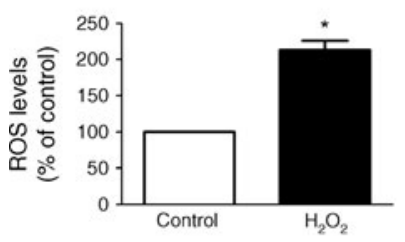

C

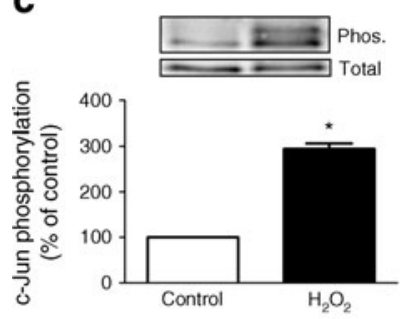

e

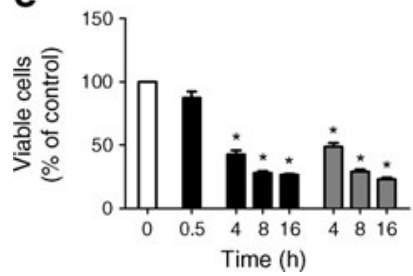

b

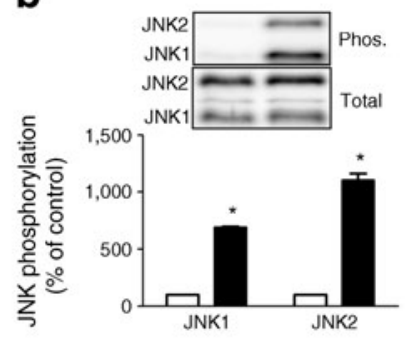

d

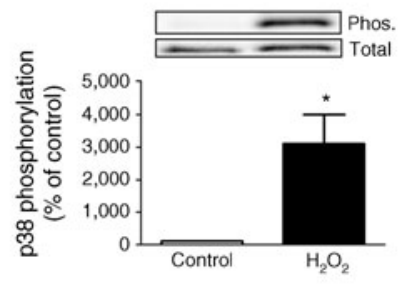

f

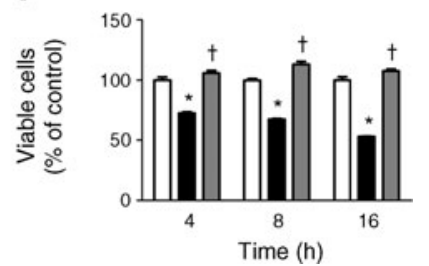

Fig. $3 \mathrm{H}_{2} \mathrm{O}_{2}$ increases ROS levels and the phosphorylation of JNK, c-Jun and p38 MAPK in MIN6 cells. Cells were treated with $0.5 \mathrm{mmol} / 1 \mathrm{H}_{2} \mathrm{O}_{2}$ (black bars) or water (control, white bars) as indicated. a ROS levels were measured using carboxy-DCF after a $30 \mathrm{~min}$ exposure. Western blot analyses of cell extracts after a $15 \mathrm{~min}$ exposure to $\mathrm{H}_{2} \mathrm{O}_{2}$ using antibodies that recognise JNK (b), c-Jun (c) or p38 MAPK (d) are shown. e MIN6 cells were treated with $\mathrm{H}_{2} \mathrm{O}_{2}$ continuously (black bars) or transiently (for $30 \mathrm{~min}$ ) and then placed in fresh medium without $\mathrm{H}_{2} \mathrm{O}_{2}$ (grey bars); cell viability was measured at the times indicated using the Cytotoxicity Detection Kit Plus. $\mathbf{f}$ The ROS scavenger, catalase, reverses the effects of $\mathrm{H}_{2} \mathrm{O}_{2}$, as shown in cells treated with $0.5 \mathrm{mmol} / 1 \mathrm{H}_{2} \mathrm{O}_{2}$ for 4,8 or $16 \mathrm{~h}$, with $250 \mathrm{U} / \mathrm{ml}$ of catalase (grey bars); cell viability was measured at the times indicated. Bars represent mean \pm SEM, $n=3-11$. * denotes a significant difference $(p<0.05)$ between $\mathrm{H}_{2} \mathrm{O}_{2}$ and controls. ${ }^{\dagger}$ denotes a significant difference $(p<0.05)$ between catalase and $\mathrm{H}_{2} \mathrm{O}_{2}$ treatments. Phos., phosphorylated

increased in cells after siRNA-mediated suppression of PP5. When compared with cells treated with a negative control siRNA, the phosphorylation of JNK2 and c-Jun was augmented in PP5 siRNA-treated cells (Fig. 6a-c). Palmitateinduced apoptosis, measured as elevated levels of cleaved caspase 3 and enhanced DNA fragmentation $24 \mathrm{~h}$ after the addition of palmitate, was also elevated in MIN6 cells after siRNA-mediated suppression of PP5 (Fig. 6d, e). These observations suggest that palmitate-induced ROS production can activate JNK in MIN6 cells, which is linked to increased apoptosis, and that PP5 acts to help protect these cells from the detrimental effects of palmitate. 
a

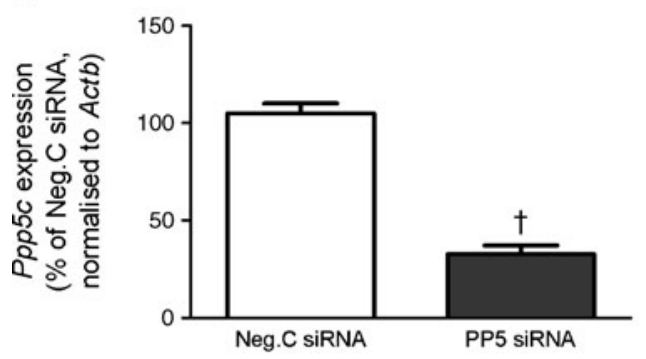

C

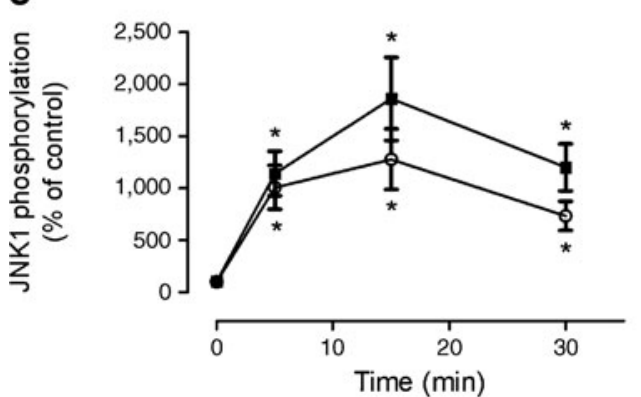

e

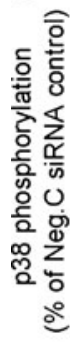

b

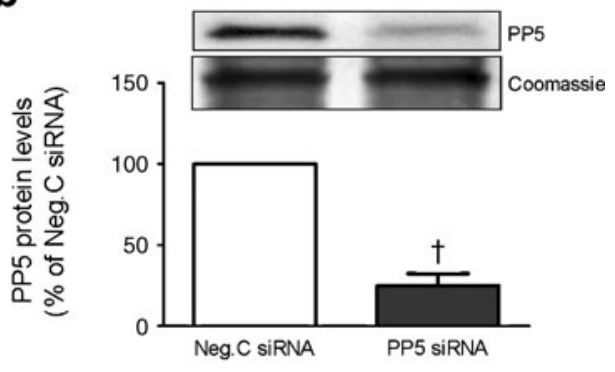

d

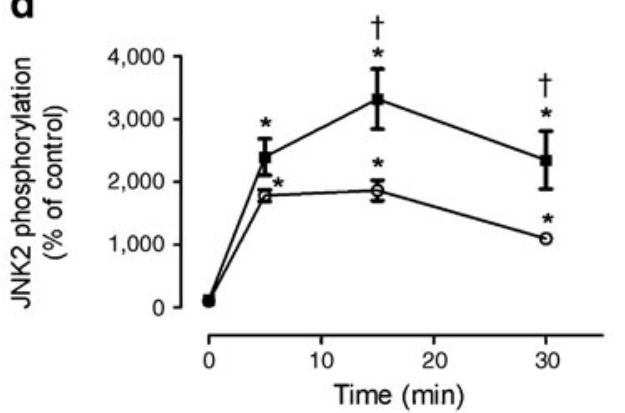

f

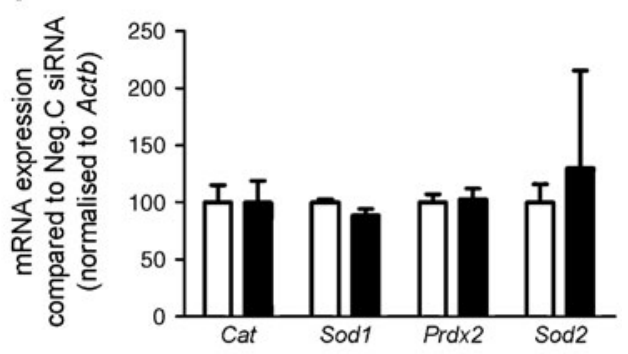

g

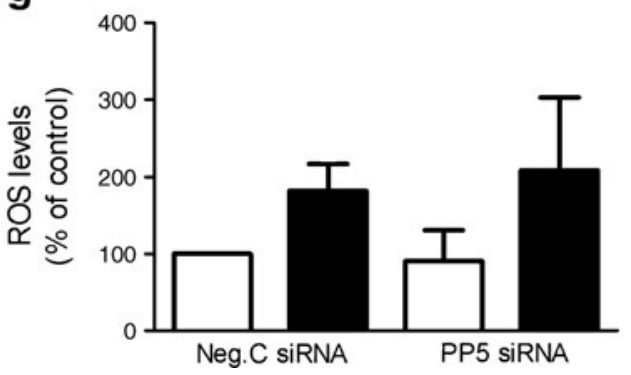

Fig. 4 PP5 suppression augments JNK phosphorylation, while p38 MAPK is unaffected, without having an apparent effect on free radicalscavenging enzymes. MIN6 cells were transfected with siRNA targeting PP5 or a negative control (Neg.C) siRNA. mRNA levels were measured $48 \mathrm{~h}$ after transfection by quantitative RT-PCR (a) and protein was detected by western blot analysis (b). After transfection $(48 \mathrm{~h})$ the cells were exposed to $0.5 \mathrm{mmol} / \mathrm{H} \mathrm{H}_{2} \mathrm{O}_{2}$ for 5,15 or $30 \mathrm{~min}$. Changes in the phosphorylation of JNK1 (c) and JNK2 (d) were detected by western blot analysis. White circles, Neg.C siRNA; black squares, PP5 siRNA. MIN6 cells were transfected as described above and exposed for $48 \mathrm{~h}$ after transfection without (control, white bars) or

Reduction of PP5 induced a state of glucose-induced hypersecretion of insulin Consistent with the results obtained from the IPGTT studies conducted with the Ppp5 $\mathrm{c}^{-/-}$mice, the with $0.5 \mathrm{mmol} / 1 \mathrm{H}_{2} \mathrm{O}_{2}$ (black bars) for $15 \mathrm{~min}$. Phosphorylation levels of p38 MAPK were measured by western blot analysis (e). f MIN6 cells were transfected as described above and the mRNA expression levels of scavenging enzymes indicated were measured by quantitative RT-PCR (white bars, Neg.C siRNA; black bars, PP5 siRNA). g Suppression of PP5 in MIN6 cells treated with $0.5 \mathrm{mmol} / 1 \mathrm{H}_{2} \mathrm{O}_{2}$ for $30 \mathrm{~min}$ (black bars) revealed no further increase in ROS levels, compared with untreated control (white bars). The data shown represent the mean $\pm \mathrm{SEM}$, $n=3-8 . *$ denotes a significant difference $(p<0.05)$ between $\mathrm{H}_{2} \mathrm{O}_{2}$ and time zero or control; ${ }^{\dagger}$ denotes a significant difference $(p<0.05)$ between Neg.C siRNA and PP5 siRNA effect

insulin secretory response to $20 \mathrm{mmol} / \mathrm{l}$ glucose was more than doubled in MIN6 cells treated with siRNA targeting PP5 compared with cells treated with negative control 

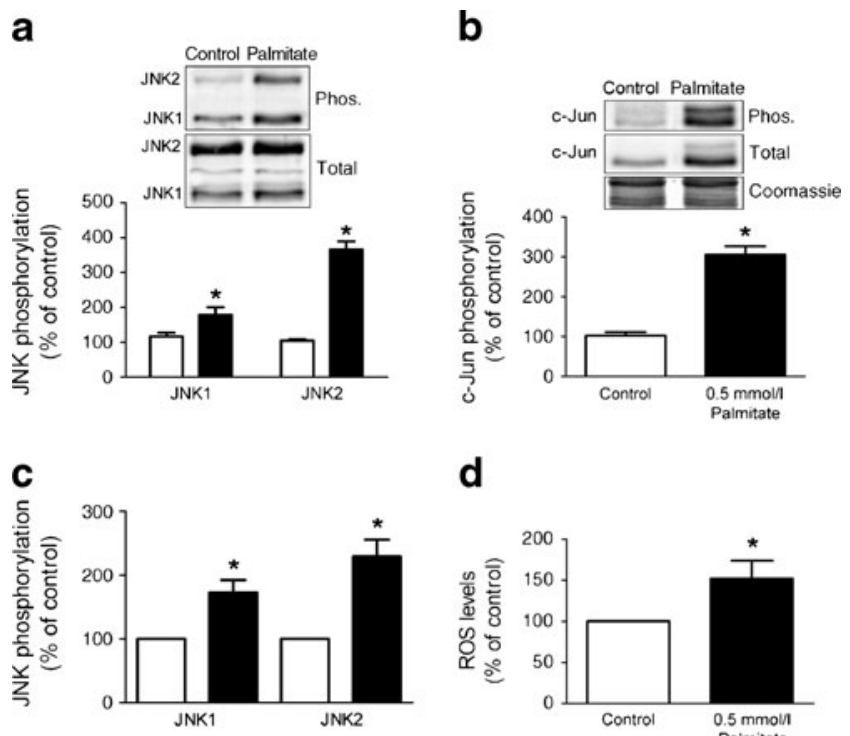

d
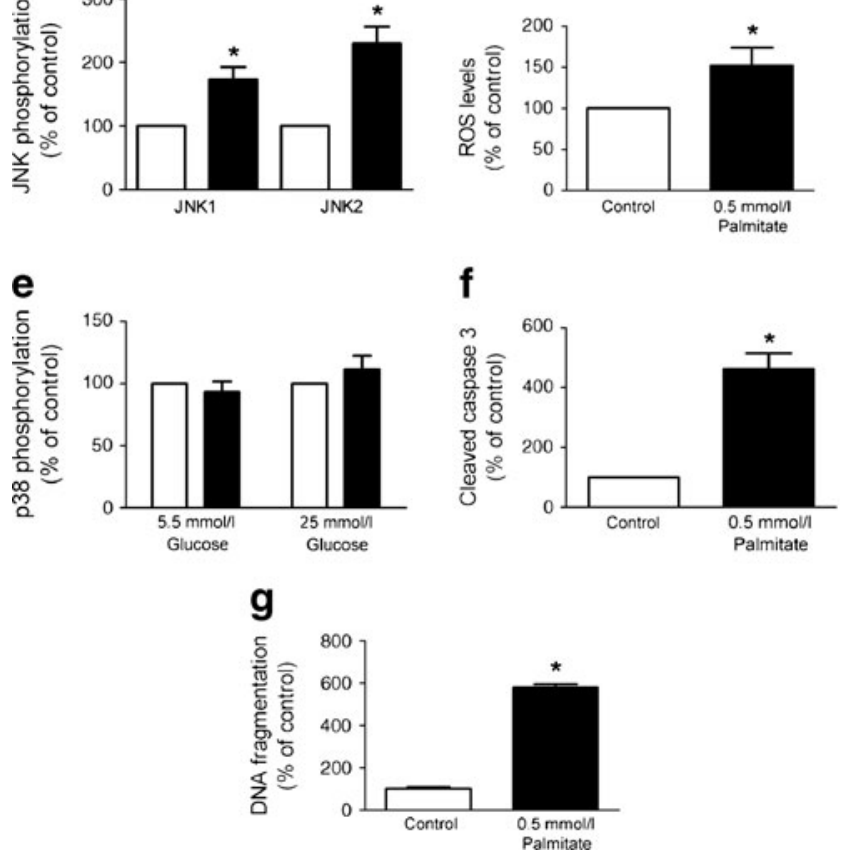

Fig. 5 Palmitate-induced apoptosis correlates with increased JNK signalling. MIN6 cells cultured in $25 \mathrm{mmol} / 1$ glucose were treated with $0.5 \mathrm{mmol} / 1$ palmitate equilibrated with $0.5 \%$ BSA (black bars), for $24 \mathrm{~h}$ compared with untreated controls (white bars). Changes in JNK (a) and c-Jun (b) phosphorylation were detected by western blot analysis. MIN6 cells were treated with or without $0.5 \mathrm{mmol} / 1$ palmitate equilibrated with $0.5 \% \mathrm{BSA}$ for $24 \mathrm{~h}$ in $5.5 \mathrm{mmol} / 1$ glucose. Changes in JNK phosphorylation (c) were detected by western blot analysis. MIN6 cells in $25 \mathrm{mmol} / \mathrm{l}$ glucose were treated with or without $0.5 \mathrm{mmol} / 1$ palmitate equilibrated with $0.5 \%$ BSA for $24 \mathrm{~h}$. ROS levels were determined by changes in the fluorescence of carboxyDCF (d). MIN6 cells were treated with or without $0.5 \mathrm{mmol} / 1$ palmitate equilibrated with $0.5 \%$ BSA for $24 \mathrm{~h}$. Phosphorylation levels of $\mathrm{p} 38$ MAPK were measured by western blot analysis in cells cultured in $5.5 \mathrm{mmol} / 1$ glucose or $25 \mathrm{mmol} / 1$ glucose (e). Cleaved caspase 3 protein levels were detected by western blot analysis (f). Apoptosis was determined by measuring cytoplasmic levels of oligonucleosomes (g). Bars represent mean \pm SEM, $n=4-8 . *$ denotes a significant difference $(p<0.05)$ between palmitate and controls. Phos, phosphorylated

siRNA (Fig. 6g). The difference remained in cells exposed to palmitate. However, no difference in insulin content of the cells was observed (Fig. 6f).
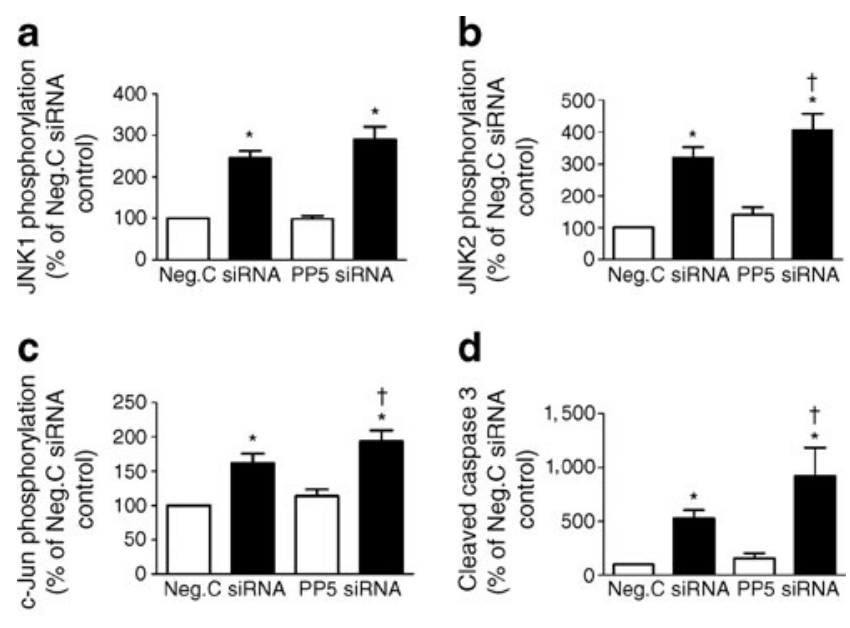

d
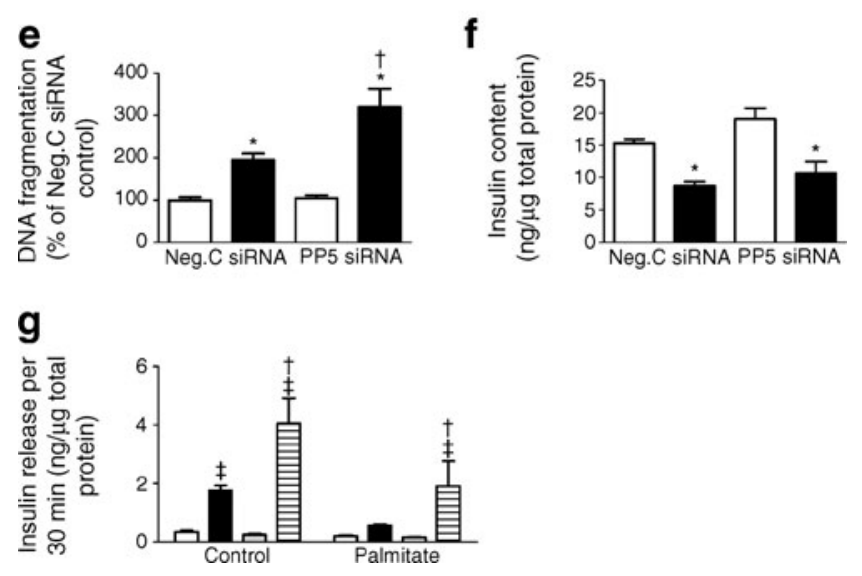

Fig. 6 PP5 suppression correlates with increased JNK signalling, augmented apoptosis and enhanced glucose-stimulated insulin secretion. MIN6 cells were treated with siRNA targeting PP5 or a negative control (Neg.C) siRNA. Cells were treated $48 \mathrm{~h}$ after transfection with $0.5 \mathrm{mmol} / 1$ palmitate equilibrated with $0.5 \%$ BSA (black bars) or $0.5 \% \mathrm{BSA} /$ solvent (controls; white bars) for $24 \mathrm{~h}$. Changes in JNK1 (a), JNK2 (b) and c-Jun (c) phosphorylation or cleaved caspase 3 protein levels (d) were detected by western blot analysis. Apoptosis was detected by measuring cytoplasmic levels of oligonucleosomes (e). Cellular insulin content (f) and glucose-stimulated insulin secretion (g) were measured by insulin ELISA. In the latter, bars are represented as follows: Neg.C siRNA in $2 \mathrm{mmol} / \mathrm{l}$ glucose (white), Neg.C siRNA in $20 \mathrm{mmol} / \mathrm{l}$ glucose (black), PP5 siRNA in $2 \mathrm{mmol} / \mathrm{l}$ glucose (grey) and PP5 siRNA in $20 \mathrm{mmol} / 1$ glucose (striped). Bars represent mean \pm SEM, $n=6-11 . *$ denotes a significant difference $(p<0.05)$ between palmitate and controls; ${ }^{\dagger}$ denotes a significant difference $(p<0.05)$ between Neg.C siRNA and PP5 siRNA effect; ${ }^{*}$ denotes a significant difference $(p<0.05)$ between 2 and $20 \mathrm{mmol} / 1$ glucose

\section{Discussion}

This paper describes, for the first time, a direct role for PP5 in pancreatic beta cells and a novel role for PP5 in the regulation of glucose homeostasis. Studies conducted in PP5 knockout mice revealed that, from 2 to 8 months of age, male $P p p 5 c^{-/-}$mice weigh less and have lower fasting glycaemia than $P p p 5 c^{+/+}$littermate controls. At 4 months of age, $P p p 5 c^{-/}$mice display higher C-peptide levels but 
unchanged fasting serum insulin levels when measured in peripheral blood. These data indicate that insulin (and C-peptide) secretion is augmented in $P p p 5 c^{-/-}$mice, which may explain why these mice have lower glucose levels. In addition, it seems that $P p p 5 c^{-/-}$mice clear insulin more efficiently, indicating that PP5 may regulate hepatic insulin clearance. In support of enhanced insulin secretion, mice lacking PP5 eliminate glucose faster than wild-type mice during an IPGTT despite unchanged insulin sensitivity. Moreover, islets from $P p p 5 c^{-/-}$mice are more sensitive to palmitate-induced JNK phosphorylation and apoptosis. Here we also report that silencing PP5 augments glucosestimulated insulin secretion in MIN6 cells without affecting the amount of insulin contained in the cells.

The enhanced secretion of insulin by cells in which PP5 has been suppressed is consistent with an earlier study showing that okadaic acid (an inhibitor of PP1, PP2A, PP4, PP5 and PP6) enhances insulin secretion in beta cells [35]. Enhanced insulin secretion in response to glucose may also explain why the $P p p 5 c^{-/-}$mice were more resistant to blood glucose increases during an IPGTT. While this study was under review, Hinds et al [25] published a report in which embryonic fibroblasts generated from another line of PP5 knockout mice were used to study the balance between lipolysis and lipogenesis. In these studies embryonic fibroblasts from mice lacking PP5 demonstrated resistance to lipid accumulation in response to adipogenic stimuli, which was due to elevated glucocorticoid receptor (GR) phosphorylation and reduced peroxisome proliferator activated receptor (PPAR) $\gamma$ activity on genes controlling lipid metabolism [25], indicating that PP5 may be a target for the treatment of obesity. Our observation that male $P p p 5 c^{-/-}$mice weigh less is consistent with this role for PP5, and in cultured human tumour cells the suppression of PP5 greatly increased dexamethasone transcriptional activation measured using a luciferase reporter assay [36]. Our observation that mice without PP5 can clear glucose more efficiently also suggests that inhibitors of PP5 may be useful for the medical management of diabetes. However, our mouse model is a total animal knockout, and, although GR phosphorylation may be regulated by PP5 in vitro, the effect of GR phosphorylation can be gene specific [37]. Therefore future studies are needed to determine if the ability of PP5 to alter glucose-stimulated insulin secretion is a direct molecular action in beta cells, and if our in vivo observations are influenced by indirect actions associated with altered adipocyte biology or altered hypothalamic control of the endocrine pancreas.

From a clinical perspective, the conclusion that inhibitors of PP5 may be useful for treating human disorders should be approached cautiously. The argument provided above suggests that inhibitors of PP5 may be useful in helping to prevent the development of type 2 diabetes, and, in the Ppp5 $\mathrm{C}^{-/-}$mice, a loss of beta cell mass was not observed.
However, results obtained with islets and MIN6 cells, in which siRNA was used to suppress PP5 expression, suggest that PP5 may also act to help protect beta cells from damage induced by palmitate. Future studies are necessary in which mice are placed on high-fat diets to determine if PP5 indeed plays a protective role in pancreatic beta cells in vivo.

Our studies also provide insight into the molecular actions of PP5 in beta cells. In MIN6 cells, changes in intracellular ROS were detected using a fluorescent DCF assay, which cannot distinguish between different types of ROS. Therefore we cannot draw conclusions about which kind of ROS are involved. However, treatment with $\mathrm{H}_{2} \mathrm{O}_{2}$ was associated with elevated phosphorylation levels of JNK, c-Jun and p38 MAPK and reduced cell viability. Silencing of PP5 expression enhanced the effects of $\mathrm{H}_{2} \mathrm{O}_{2}$ on JNK and c-Jun phosphorylation, without producing an increase in basal DCF fluorescence, decreasing the production of ROS scavenging enzymes, or altering p38 MAPK phosphorylation. Treatment with palmitate produced a similar response in MIN6 cells. The effects of palmitate on JNK and c-Jun phosphorylation were similar in both low and high glucose, indicating that palmitate-mediated activation of $\mathrm{JNK}$ is not glucose-dependent. These observations are in agreement with previous studies conducted in other cell types that also indicate that PP5 acts to suppress a JNK-mediated response favouring apoptosis after ROS-induced stress [21-24, 38, 39]. Since other protein phosphatases, most notably PP $2 A$ [39], have been shown to affect JNK phosphorylation, it was important to exclude compensatory changes in the levels of other phosphatases after manipulation of PP5. We observed no changes in the mRNA expression levels of Ppplca, Ppp 2ca and Ppp3ca and, importantly, PP2A activity was not changed after PP5 silencing.

Both our studies and the results reported by Hinds et al [25] suggest that PP5 may play a previously unrecognised role in glucose and lipid metabolism. Additional studies are necessary to further address the role of PP5 in beta cell function and glucose homeostasis. Studies are needed to determine if PP5 affects the regulation of GR- and PPARmediated gene expression in vivo. Molecular studies are needed to determine if the observed increase in glucose homeostasis is due to a direct or indirect role for PP5 in the regulation of insulin secretion. Furthermore, since the activation of JNK is triggered during endoplasmic reticulum stress [40, 41], it may also be interesting to investigate the possibility that PP5 functions as a negative regulator of such stress-mediated apoptosis. The development of small molecules that modulate PP5 activity should be very useful for further study of PP5. It will be interesting to see if an inhibitor of PP5 can suppress weight gain or prevent progression from glucose tolerance to diabetes, without harming pancreatic beta cells exposed to an environment with elevated ROS. Alternatively, compounds that activate PP5 
may confer protection against lipotoxicity in beta cells. In contrast, studies in which PP5 is upregulated by forced overexpression may provide limited information. This is because PP5 consists of a single polypeptide chain, with a catalytic domain near the $\mathrm{C}$-terminus and both regulatory and targeting tetratricopeptide repeat (TPR) domains in the N-terminal regions [42, 43]. In solution, PP5 has little catalytic activity because the TPR domains fold over the catalytic site blocking substrate access [44]. This state of autoinhibition is reversed when PP5 binds to another protein via its TPR domains, which triggers a conformational change that 'activates' PP5 by allowing substrate access to the catalytic site [45]. Hence, forced overexpression of PP5 may only produce a pool of unbound PP5 proteins without enzymatic activity [45].

In conclusion, our data provide evidence that PP5 is a previously unrecognised player in the regulation of pancreatic beta cell apoptosis and glucose homeostasis. We show that islets from Ppp5 $c^{-/-}$mice and MIN6 cells with suppressed PP5 expression display increased sensitivity towards palmitate- and $\mathrm{H}_{2} \mathrm{O}_{2}$-induced cytotoxicity. In mice, the genetic disruption of PP5 was associated with reduced weight gain, lower fasting glycaemia, increased glucoseinduced insulin secretion, and improved glucose tolerance during IPGTT. Thus, PP5 may represent an underappreciated player in the development and progression of diabetes.

Acknowledgements We thank the personnel at the animal facility of Södersjukhuset for excellent animal care.

Funding This study was supported by grants from the Olle Engkvist Byggmästare Foundation, Diabetes Research and Wellness Foundation, Berth von Kantzow's Foundation, Golje's Memorial Foundation and Eva and Oscar Ahrén's Foundation. H. Ortsäter is funded by the Swedish Society for Medical Research.

Duality of interest The authors declare that there is no duality of interest associated with this manuscript.

Contribution statement NG performed experiments, analysed and interpreted data and drafted the manuscript. LA helped develop the $P_{p p 5 c^{-/}}$mice, interpreted data and revised the manuscript. REH and ÅS contributed to design, interpretation and discussion of data, revised the manuscript and provided expertise in protein phosphatases and diabetes. HO was responsible for the conception of the study and drafted the manuscript. All authors have read and approved the final version of the manuscript.

\section{References}

1. Marena S, Montegrosso G, de Michieli F, Pisu E, Pagano G (1992) Comparison of the metabolic effects of mixed meal and standard oral glucose tolerance test on glucose, insulin and C-peptide response in healthy, impaired glucose tolerance, mild and severe non-insulin-dependent diabetic subjects. Acta Diabetol 29:29-33
2. Polonsky KS, Given BD, Hirsch L et al (1988) Quantitative study of insulin secretion and clearance in normal and obese subjects. J Clin Invest 81:435-441

3. Butler AE, Janson J, Bonner-Weir S, Ritzel R, Rizza RA, Butler PC (2003) $\beta$-Cell deficit and increased $\beta$-cell apoptosis in humans with type 2 diabetes. Diabetes 52:102-110

4. Pick A, Clark J, Kubstrup C et al (1998) Role of apoptosis in failure of $\beta$-cell mass compensation for insulin resistance and $\beta$-cell defects in the male Zucker diabetic fatty rat. Diabetes 47:358-364

5. Sjöholm Å (1996) Diabetes mellitus and impaired pancreatic betacell proliferation. J Intern Med 239:211-220

6. Oprescu AI, Bikopoulos G, Naassan A et al (2007) Free fatty acidinduced reduction in glucose-stimulated insulin secretion: evidence for a role of oxidative stress in vitro and in vivo. Diabetes 56:2927-2937

7. Koshkin V, Wang X, Scherer PE, Chan CB, Wheeler MB (2003) Mitochondrial functional state in clonal pancreatic beta-cells exposed to free fatty acids. J Biol Chem 278:19709-19715

8. Sakai K, Matsumoto K, Nishikawa T et al (2003) Mitochondrial reactive oxygen species reduce insulin secretion by pancreatic $\beta$-cells. Biochem Biophys Res Commun 300:216-222

9. Lupi R, Dotta F, Marselli L et al (2002) Prolonged exposure to free fatty acids has cytostatic and pro-apoptotic effects on human pancreatic islets: evidence that $\beta$-cell death is caspase mediated, partially dependent on ceramide pathway, and Bcl-2 regulated. Diabetes 51:1437-1442

10. Lenzen S, Drinkgern J, Tiedge M (1996) Low antioxidant enzyme gene expression in pancreatic islets compared with various other mouse tissues. Free Radic Biol Med 20:463-466

11. Tiedge M, Lortz S, Drinkgern J, Lenzen S (1997) Relation between antioxidant enzyme gene expression and antioxidative defense status of insulin-producing cells. Diabetes 46:1733-1742

12. Ichijo H, Nishida E, Irie K et al (1997) Induction of apoptosis by ASK1, a mammalian MAPKKK that activates SAPK/JNK and p38 signaling pathways. Science 275:90-94

13. Nishitoh H, Saitoh M, Mochida Y et al (1998) ASK1 is essential for JNK/SAPK activation by TRAF2. Mol Cell 2:389-395

14. Widenmaier SB, Ao Z, Kim SJ, Warnock G, McIntosh CH (2009) Suppression of $\mathrm{p} 38$ MAPK and JNK via Akt-mediated inhibition of apoptosis signal-regulating kinase 1 constitutes a core component of the $\beta$-cell pro-survival effects of glucose-dependent insulinotropic polypeptide. J Biol Chem 284:30372-30382

15. Hattori K, Naguro I, Runchel C, Ichijo H (2009) The roles of ASK family proteins in stress responses and diseases. Cell Commun Signal 7:9

16. Saitoh M, Nishitoh H, Fujii M et al (1998) Mammalian thioredoxin is a direct inhibitor of apoptosis signal-regulating kinase (ASK) 1. EMBO J 17:2596-2606

17. Tobiume K, Saitoh M, Ichijo H (2002) Activation of apoptosis signal-regulating kinase 1 by the stress-induced activating phosphorylation of pre-formed oligomer. J Cell Physiol 191:95-104

18. Matsuzawa A, Nishitoh H, Tobiume K, Takeda K, Ichijo H (2002) Physiological roles of ASK1-mediated signal transduction in oxidative stress- and endoplasmic reticulum stress-induced apoptosis: advanced findings from ASK1 knockout mice. Antioxid Redox Signal 4:415-425

19. Chinkers M (2001) Protein phosphatase 5 in signal transduction. Trends Endocrinol Metab 12:28-32

20. Honkanen RE, Golden T (2002) Regulators of serine/threonine protein phosphatases at the dawn of a clinical era? Curr Med Chem 9:2055-2075

21. Zhou G, Golden T, Aragon IV, Honkanen RE (2004) Ser/Thr protein phosphatase 5 inactivates hypoxia-induced activation of an apoptosis signal-regulating kinase $1 / \mathrm{MKK}-4 / \mathrm{JNK}$ signaling cascade. J Biol Chem 279:46595-46605 
22. Morita K, Saitoh M, Tobiume K et al (2001) Negative feedback regulation of ASK1 by protein phosphatase 5 (PP5) in response to oxidative stress. EMBO J 20:6028-6036

23. Huang S, Shu L, Easton J et al (2004) Inhibition of mammalian target of rapamycin activates apoptosis signal-regulating kinase 1 signaling by suppressing protein phosphatase 5 activity. J Biol Chem 279:36490-36496

24. Kutuzov MA, Andreeva AV, Voyno-Yasenetskaya TA (2005) Regulation of apoptosis signal-regulating kinase 1 (ASK1) by polyamine levels via protein phosphatase 5. J Biol Chem 280:25388-25395

25. Hinds TD Jr, Stechschulte LA, Cash HA et al (2011) Protein phosphatase 5 mediates lipid metabolism through reciprocal control of glucocorticoid receptor and peroxisome proliferator-activated receptor-gamma (PPARgamma). J Biol Chem 286:42911-42922

26. Yong W, Bao S, Chen H, Li D, Sanchez ER, Shou W (2007) Mice lacking protein phosphatase 5 are defective in ataxia telangiectasia mutated (ATM)-mediated cell cycle arrest. J Biol Chem 282:14690 14694

27. Amable L, Grankvist N, Largen JW, Ortsäter H, Sjöholm A, Honkanen RE (2011) Disruption of serine/threonine protein phosphatase 5 (PP5:PPP5c) in mice reveals a novel role for PP5 in the regulation of ultraviolet light-induced phosphorylation of serine/ threonine protein kinase Chk1 (CHEK1). J Biol Chem 286:4041340422

28. Miyazaki J, Araki K, Yamato E et al (1990) Establishment of a pancreatic $\beta$ cell line that retains glucose-inducible insulin secretion: special reference to expression of glucose transporter isoforms. Endocrinology 127:126-132

29. Suh KS, Chon S, Oh S et al (2009) Prooxidative effects of green tea polyphenol (-)-epigallocatechin-3-gallate on the HIT-T15 pancreatic beta cell line. Cell Biol Toxicol 26:189-199

30. Sargsyan E, Ortsäter H, Thörn K, Bergsten P (2008) Diazoxideinduced $\beta$-cell rest reduces endoplasmic reticulum stress in lipotoxic $\beta$-cells. J Endocrinol 199:41-50

31. Lowry OH, Rosebrough NJ, Farr AL, Randall RJ (1951) Protein measurement with the Folin phenol reagent. J Biol Chem 193:265275

32. Bock T, Pakkenberg B, Buschard K (2003) Increased islet volume but unchanged islet number in ob/ob mice. Diabetes 52:1716-1722

33. Kharroubi I, Ladriere L, Cardozo AK, Dogusan Z, Cnop M, Eizirik DL (2004) Free fatty acids and cytokines induce pancreatic $\beta$-cell apoptosis by different mechanisms: role of nuclear factor- $\mathrm{kB}$ and endoplasmic reticulum stress. Endocrinology 145:5087-5096

34. Cunha DA, Hekerman P, Ladriere L et al (2008) Initiation and execution of lipotoxic ER stress in pancreatic $\beta$-cells. J Cell Sci 121:2308-2318

35. Sjöholm A, Lehtihet M, Efanov AM, Zaitsev SV, Berggren PO, Honkanen RE (2002) Glucose metabolites inhibit protein phosphatases and directly promote insulin exocytosis in pancreatic $\beta$-cells. Endocrinology 143:4592-4598

36. Zuo Z, Urban G, Scammell JG et al (1999) Ser/Thr protein phosphatase type 5 (PP5) is a negative regulator of glucocorticoid receptor-mediated growth arrest. Biochemistry 38:8849-8857

37. Chen W, Dang T, Blind RD et al (2008) Glucocorticoid receptor phosphorylation differentially affects target gene expression. Mol Endocrinol 22:1754-1766

38. Sanchez-Ortiz E, Hahm BK, Armstrong DL, Rossie S (2009) Protein phosphatase 5 protects neurons against amyloid- $\beta$ toxicity. J Neurochem 111:391-402

39. Chen L, Liu L, Yin J, Luo Y, Huang S (2009) Hydrogen peroxideinduced neuronal apoptosis is associated with inhibition of protein phosphatase $2 \mathrm{~A}$ and 5 , leading to activation of MAPK pathway. Int J Biochem Cell Biol 41:1284-1295

40. Ortsäter H, Sjöholm A (2007) A busy cell-endoplasmic reticulum stress in the pancreatic $\beta$-cell. Mol Cell Endocrinol 277:1-5

41. Eizirik DL, Cardozo AK, Cnop M (2008) The role for endoplasmic reticulum stress in diabetes mellitus. Endocr Rev 29:42-61

42. Chen MX, McPartlin AE, Brown L, Chen YH, Barker HM, Cohen PT (1994) A novel human protein serine/threonine phosphatase, which possesses four tetratricopeptide repeat motifs and localizes to the nucleus. EMBO J 13:4278-4290

43. Becker W, Kentrup H, Klumpp S, Schultz JE, Joost HG (1994) Molecular cloning of a protein serine/threonine phosphatase containing a putative regulatory tetratricopeptide repeat domain. J Biol Chem 269:22586-22592

44. Kang H, Sayner SL, Gross KL, Russell LC, Chinkers M (2001) Identification of amino acids in the tetratricopeptide repeat and Cterminal domains of protein phosphatase 5 involved in autoinhibition and lipid activation. Biochemistry 40:10485-10490

45. Yang J, Roe SM, Cliff MJ et al (2005) Molecular basis for TPR domain-mediated regulation of protein phosphatase 5. EMBO J 24:1-10 